\title{
El concepto de derecho. Foucault, la ley y la crítica del paradigma liberal
}

ERNESTO MIELES*

En 1966 Michel Foucault creía que la ley era omnipresente. En El pensamiento del afuera, corto escrito en el cual examinó la obra de Blanchot desde la perspectiva inaugurada por Las palabras y las cosas, sostuvo que "la ley, soberanamente, asedia las ciudades, las instituciones, las conductas y los gestos; se haga lo que se haga, por grandes que sean el desorden y la incuria, ella ya ha desplegado sus poderes" (p. 44).

Menos de diez años después, en Vigilar y castigar, el filósofo francés habría de cambiar de posición. En esta obra sostendría el fin del derecho, o más exactamente, el fin del paradigma teórico jurídico liberal, de acuerdo con el cual el derecho es el principal instrumento de regulación y normalización de las sociedad modernas.

El propósito de este escrito es proponer trazos para el entendimiento de ese viraje, de ese giro que sin lugar a dudas tendrá un impacto decisivo en la reflexión teórico jurídica. En suma, se trata de verificar cuál es el concepto de derecho que está inscrito en la matriz filosófica foucaultiana, escudriñada recientemente por pensadores comprometidos con la denuncia de la violencia como elemento constitutivo del derecho.

\section{La ley está en todas partes}

Michel Foucault se preguntó a sí mismo ¿dónde está la ley?, y respondió en El pensamiento del afuera: hasta en los intersticios más invisibles. Puesto que regula todas las actividades, todos los movimientos, todas las conductas; puesto que las prevé, la ley es omnipresente. Incluso cuando no se expresa más que como sanción, es decir, más que como reacción ante la infracción, la ley está presente. La desobediencia no implica la desaparición, siquiera momentánea, de la ley, sino su reafirmación. Según Foucault (Blanchot), "pueden muy bien formarse complots, extenderse rumores de sabotaje; los incendios, los asesinatos, pueden muy bien ocupar el lugar del orden más ceremonioso; el orden de la ley no habrá sido jamás tan soberano, puesto que ahora abarca todo aquello que quiere derribarIo" (p. 52). 
Así, el desobediente es también un agente de la ley, es un ejecutor de la legalidad burguesa. Sus actos contribuyen a potenciar los efectos de la ley. En palabras del propio Foucault, "las libertades no son capaces de interrumpirla; uno puede llegar a creer que se ha desentendido de ella, que observa desde fuera su aplicación; en el momento en que se cree estar leyendo de lejos los secretos válidos sólo para los demás, uno no puede estar más cerca de la ley" (p. 44).

No existe un afuera de la ley. En consecuencia, no podemos pensar en el afuera de la ley. Es imposible imaginar ese afuera porque nuestra imaginación es esencialmente imaginación jurídica. El poder no lo concentra la institucionalidad, por cuanto es gestionado desde la imaginación jurídica, y ésta nos condiciona a la hora de imaginar alternativas. Sencillamente estamos inmersos en la ley, al tiempo que la ley está inmersa en nosotros; define nuestra identidad; constituye una acabada articulación de significados a través de los cuales vivimos. Por esta razón no tiene sentido distinguir entre alta cultura jurídica y derecho pop.

Como bien lo anotaba Foucault, "el afuera de la ley es tan inaccesible que cuando se quiere superarlo y penetrar en él se está abocado, no ya al castigo que sería la ley finalmente violada, sino al afuera de ese afuera mismo -a un olvido más profundo que todos los demás" (p. 48)'1.

Foucault anticipó así el análisis cultural del derecho. De acuerdo con éste, las cosas no pueden ser de otro modo. "Gane quien gane nosotros perdemos", en la conocida formulación de Paul Kahn. Es decir, la integridad del derecho (esa que guarda Hércules) nunca está en juego en los litigios particulares. La lógica de la ley permanece intacta, aún en los casos controvertidos; no se altera ni ante la enjundia de la jurisprudencia progresista.

En últimas, el derecho exige cualquier resultado. Por eso hay que abandonar el mito del progreso. A partir de ahora no puede insistirse en el potencial emancipatorio del derecho (contrario a lo proyectado por Boaventura de Sousa Santos desde Coimbra y Wisconsin, o García Villegas y Uprimny desde Bogotá). En este contexto, iquién puede anunciar el advenimiento de un nuevo derecho? ¿Quién puede atreverse a reivindicar la teoría del poder constituyente? ¿Quién está dispuesto a seguir defendiendo la argumentación jurídica si no hay en verdad conflictos de significación?² ¿Qué sentido tiene buscar la legitimidad vía legalidad?

En contravía de Luhmann, Foucault plantea en $\mathrm{EI}$ pensamiento del afuera que la ley no tiene entorno. La ley es el aire que respiramos ${ }^{3}$. Es un cúmulo de creencias y deseos. Es preciso desechar entonces la sugerencia del análisis económico del derecho, de entender el Estado de derecho como el producto de un diseño racional destinado a producir resultados eficientes ${ }^{4}$. Contrario a lo que pensaba Weber, el derecho no se racionaliza en la modernidad. La desacralización del derecho es pura ficción, como también lo es la teoría pura del derecho.

1 En "Nomos y narración", Robert Cover sostiene que "una gran civilización jurídica se caracteriza por la riqueza del nomosen el cual está situada y al cual contribuye a constituir. El variado y complejo material de ese nomos establece paradigmas de consagración, resignación, contradicción y resistencia. Este material no sólo presenta cuerpos de reglas o doctrina que requieren interpretación, sino mundos para habitar. Habitar un nomos es saber cómo vivir en él" (p. 18).

2 Sobre el problema de la interpretación del derecho en Foucault, véase el artículo "Foucault and (The Ideology of) Genealogical Legal Theory" de Jerry Leonard.

3 Este párrafo es resultado de la adaptación del análisis cultural del derecho propuesto en Colombia por David Valencia Villamizar. En criterio de este autor, "la cultura es el aire que respiramos, pero también es la antimateria de la que está hecho este aire. Semiosfera, no alcanza la esfera completa y es todo, el medio ambiente simbólico, el hábitat de las ideologías". Koyaanisqatsi, la desinencia de la DIOS-a madre.

4 De acuerdo con una tradición que se remonta a William James y que representa actualmente Jon Elster, creamos leyes para evitar decidir en contextos de incertidumbre. La creación de normas es entonces una actividad racional. Obsérvense las coincidencias con la teoría sociológica del derecho de Niklas Luhmann. 
En síntesis, el Estado de derecho no tiene límites, por cuanto el derecho se ha procedimentalizado para reclamar la totalidad del yo. La juridificación de la sociedad, el malestar en la cultura, se ha completado. El Estado de derecho ha logrado contener la muchedumbre, ha transformado la multiplicidad en unidad (Guardiola -Rivera).

\section{Reconsiderando el papel del derecho en la sociedad disciplinaria}

La genealogía del poder punitivo condujo a Foucault a negar lo dicho en El pensamiento del afuera. En Vigilar y castigar el historiador francés sostiene que la ley no logra penetrar los dispositivos disciplinarios donde se produce la subjetivación. En estos dispositivos (erigidos a imagen y semejanza del Panóptico) opera un no-derecho, una especie de infra-derecho:

"Nuestras sociedades y los poderes que en ella se ejercen están situadas bajo el signo visible de la ley. Pero, de hecho, los mecanismos más numerosos, los más eficaces $y$ persistentes operan en el intersticio de las leyes según modalidades distintas al derecho y en función de un objetivo que no es el respeto de la legalidad" (p. 67).

Como lo ha precisado el profesor Sauquillo en "Michel Foucault, una crítica del control social moderno":

"[...]el poder normalizante que se constituye a principios del siglo XIX, según este punto de vista, no interviene tanto por la ley como por la norma; se trata de un control social extrajurídico que se origina en los intersticios del derecho penal, contemporáneamente al auge de la teoría del 'control social' y de la división de poderes" (p. 273).
Y más adelante:

“La concepción jurídica del poder subraya la obligatoriedad de la ley, pero, en opinión de Foucault, ésta no regula la organización social. En la vinculatoriedad de las normas sólo se da el resultado más minúsculo del gobierno político. La estrategia del poder, para el escritor de Surveiller et punir, es más insidiosa que la puramente normativa: atraviesa el cuerpo social y lo produce, no tanto a través de la ley como de las disciplinas, no tanto a través de la prohibición como de la incitación a la seducción y la producción de saber... Los métodos punitivos, desde la perspectiva de Foucault, no son el efecto material de las reglas de derecho o de las estructuras sociales sino de técnicas más complejas de poder" (p. 274)

El infra-derecho es el instrumento de normalización inmanente a la sociedad disciplinaria, esto es, la sociedad de vigilancia donde ha operado la distinción entre lo público y lo privado, donde la observación sobre los cuerpos puede ser realizada ininterrumpidamente. El infra-derecho es el esquema regulativo propio de isomorfos dispositivos disciplinarios - remember las similitudes que se dan entre la escuela, en la cual la extracción de saber y el ejercicio de poder están articulados por la pedagogía, y la prisión, en la cual se realiza un examen de la delincuencia para extraer saber de los internos y ejercer un poder sobre ellos.

La genealogía evidencia la subjetivación constante, esto es, la creación permanente de sujetos con una identidad bien definida -el homosexual, el heterosexual, el delincuente, la persona de bien, el buen estudiante, el inadaptado, el enfermo, el sano, el vago, el trabajador, etc. - , como la característica de la sociedad moderna. Esta subjetivación se basa en una doble estrategia: de un lado, los dispositi- 
vos de poder escinden a unos individuos de otros, los aíslan asignándoles unas características; y de otro lado, estos dispositivos atribuyen una identidad al sujeto; en todo el proceso, la exacción y la violencia resultan menos importantes que la vigilancia y el control. El poder es transversal, estratégico e inmediato. El funcionamiento de las sociedades modernas, la producción de plusvalía (económica y política), es posible por la existencia de mecanismos de poder. Estos mecanismos operan intensivamente para producir individuos y aumentar las utilidades con el menor esfuerzo y en el menor tiempo posible.

Las sociedades de la antigüedad clásica fueron sociedades del espectáculo, pues el público observaba al individuo -típicamente en los espectáculos de sangre, como los llevados a cabo en el coliseo. En cambio, las sociedades modernas son sociedades de la vigilancia. El postulado de las sociedades del espectáculo ha sido invertido: ahora uno observa a muchos o a todos. Esta es la inversión que hace posible la separación entre el Estado y el mercado. En principio no es posible escapar a la vigilancia, debido a que ésta es ejercida en todo el entramado social. La encontramos en los modelos de atención psiquiátrica, en la fábrica, en la empresa, en la escuela, en la prisión, etc. En un universo a-céntrico, el control se ejerce de manera dispersa.

El Estado no acumula todo el poder social y político, por lo cual es necesario estudiar la microfísica del poder, puesto que es en los dispositivos donde se ejerce y se distribuye el poder. Así, de un lado tenemos los códigos, en los que se establece la democracia representativa o participativa, según sea el caso, así como los derechos civiles y políticos (empezando por la igual libertad para todos que solía exigir Rawls), es decir, la forma jurídica general; $y$ de otro lado encontramos los dispositivos disciplinarios, donde se asimila a los individuos al mismo tiempo que se los diferencia a través de un infra-derecho, esto es, de un conjunto de estándares que constituyen guías para la conducta, razones para la acción, parámetros de corrección y referentes para el castigo. Las normas que componen el infra-derecho, pero no la ley, estipulan lo normal y definen lo desviado (Hunt).

\section{Del infra-derecho al derecho como instrumento de guerra}

Vigilar y castigar debe ser entendido entonces como un análisis detallado del infra-derecho. El aparente descuido de Foucault por la ley será subsanado, no obstante, en Defender la sociedad, el curso dictado en el Colegio de Francia en el ciclo lectivo 19751976.

El derecho es la continuación de la guerra por otros medios, declara Foucault en Defender la sociedad, invirtiendo con esta enunciación el aforismo de Clausewitz. El lenguaje del derecho no es el lenguaje de la paz, sino la reverberación de las bataIlas. Los pactos sociales no son pactos de paz, sino pactos de guerra, cartas de batalla por medio de los cuales se distribuye el poder político. Puesto que las reglas de derecho expresan los resultados de esa distribución y la convierten en permanente, el post-conflicto es radicalmente imposible. En palabras del mismo Foucault:

"Las relaciones de poder, tal como funcionan en una sociedad como la nuestra, tienen esencialmente por punto de anclaje cierta relación de fuerza establecida en un momento dado, históricamente identificable, en la guerra y por la guerra. Y si bien es cierto que el poder político detiene la guerra, hace reinar o intenta hacer reinar una paz en la sociedad civil, o lo hace en absoluto para neutralizar los efectos de aquélla o el desequilibrio que se manifestó en su batalla final. En esta hipótesis, el papel del poder político sería reinscribir perpetuamente esa 
relación de fuerza, por medio de una guerra silenciosa, y reinscribirla en las instituciones, en las desigualdades económicas, en el lenguaje, hasta en los cuerpos de unos y otros... dentro de esa paz civil, las luchas políticas, los enfrentamientos con respecto al poder, con el poder, por el poder, las modificaciones de las relaciones de fuerza acentuaciones de un lado, inversiones, etcétera-, todo eso, en un sistema político, no debería interpretarse sino como las secuelas de la guerra" (pp. 28-29).

La ley colombiana ejemplifica bien el postulado foucaultiano. En Colombia la praxis jurídica ha sido en buena parte una praxis autoritaria. En este país, un uso recurrente del estado de excepción durante más de cincuenta años que abre posibilidades para un ejercicio autoritario del poder, ha ritualizado la violencia (García Villegas y Rodríguez). El estado de excepción es en esencia la continuación de la guerra, del conflicto armado interno, por otros medios.

Foucault coincide entonces con Paul Kahn, quien propone un análisis cultural del derecho donde la violencia es entendida como un elemento constitutivo del Estado de Derecho. Y también coincide con Boaventura de Sousa Santos, para quien el derecho es siempre el resultado de la interacción variable entre retórica, burocracia y violencia. Por lo mismo, se distancia de Habermas, cuya teoría jurídica se estructura en torno a la negación tajante de la violencia: sólo pueden ser consideradas válidas las normas cuyas consecuencias y efectos secundarios pueden ser aceptados libremente -sin coacción alguna- por todos los eventuales afectados.

En consecuencia, para Foucault el derecho no es literatura (como, por el contrario, lo quiere hacer ver en nuestro medio Beatriz Espinosa Pérez); es, en cambio, un verdadero instrumento de guerra que encubre una estrategia de gobernamentalidad total sobre la sociedad (Foucault, Sauquillo, Ewald); gobernamentalidad que, valga subrayarlo, en países semi -periféricos como el colombiano, hace parte de un proceso de extracción, de despojo, de acumulación originaria, que articula un programa en el cual "gobernar es repoblar" (Kraniauskas, Herrera, CODHES), mientras en el plano mundial equivale a la administración de la sociedad global de control (Deleuze, Negri \& Hardt).

\section{Bibliografía}

Consultoría para los derechos humanos y el desplazamiento (CODHES). Un país que huye. Desplazamiento y violencia en una nación fragmentada. Bogotá: UNICEF / CODHES, 2003.

COVER, Robert, "Nomos y narración". En: COVER, Robert. Derecho, narración y violencia. Poder constructivo y poder destructivo en la interpretación judicial. Barcelona: Gedisa / Yale Law School, 2002.

DELEUZE, Gilles, "Pos-scriptum sobre las sociedades de control". En: DELEUZE, Gilles Conversaciones. Valencia: Pre-textos, 1995.

ESPINOSA PÉREZ, Beatriz: Narraciones en el campo jurídico. Bogotá: Pontificia Universidad Javeriana, 2003, multicopiado.

FOUCAULT, Michel. Vigilar y castigar. México: Siglo XXI, 1976.

FOUCAULT, Michel. "La gubernamentalidad". En: Michel Foucault et al. Espacios de poder. Madrid: La Piqueta, 1981.

FOUCAULT, Michel. El pensamiento del afuera. Valencia: Pre-textos, 2000.

FOUCAULT, Michel. Defender la sociedad. México: Fondo de Cultura Económica, 2001.

GARCÍA VILLEGAS, Mauricio y RODRÍGUEZ, César. Derecho y sociedad en América Latina: un debate 
sobre los estudios jurídicos críticos. Bogotá: ILSA / Universidad Nacional de Colombia.

GUARDIOLA RIVERA, Óscar. El futuro de una ilusión. Reporte sobre el porvenir del derecho desde la perspectiva de la teoría jurídica. Bogotá: Pontificia Universidad Javeriana, 2004, multicopiado.

HERRERA ÁNGEL, Martha. Ordenar para controlar. Bogotá: Academia Colombiana de Historia / Instituto Colombiano de Antropología e Historia, 2002.

HUNT, Alan. "Foucault's Expulsion of Law: Toward a Retrieval". En: HUNT, Alan. Explorations in Law and Society: Toward a Constitutive Theory of Law (After the Law). Nueva York y Londres: Routledge, 1993.

KAHN, Paul. El análisis cultural del derecho. Una reconstrucción de los estudios jurídicos. Barcelona: Gedisa / Yale Law School, 2001.

KRANIAUSKAS, John. "Gobernar es repoblar: de la acumulación originaria neo -liberal". Londres, Birbeck collage, Universidad de Londres, manuscrito.
LEONARD, Jerry, "Foucault and (The Ideology of) Genealogical Legal Theory". En: LEONARD, Jerry (editor). Legal studies as cultural studies: a reader in (post) modern critical theory. Albany: State of New York University Press, 1995.

NEGRI, Antonio y HARDT, Michael. Imperio. Buenos Aires: Paidós, 2003.

SANTOS, Boaventura de Sousa. Estado, derecho y luchas sociales. Bogotá: ILSA, 1991.

Sauquillo, Julián. "Michel Foucault. Una crítica del control social moderno". En: GARCÍA AMADO, Juan Antonio (coord.). El derecho en la teoría social. Diálogo con catorce propuestas actuales. Madrid: Dykinson, 2001.

VALENCIA VILLAMIZAR, David. "Koyaanisqatsi, la desinencia de la DIOS-a madre". Bogotá: Universidad Santo Tomás, 2004, multicopiado. 